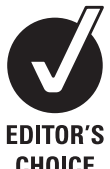

CHOICE

\title{
Risk of injury for bicycling on cycle tracks versus in the street
}

\author{
Anne C Lusk, ${ }^{1}$ Peter G Furth, ${ }^{2}$ Patrick Morency, ${ }^{3,4}$ Luis F Miranda-Moreno, ${ }^{5}$ \\ Walter C Willett, ${ }^{1,6}$ Jack T Dennerlein ${ }^{7,8}$
}

${ }^{1}$ Department of Nutrition, Harvard School of Public Health, Boston, MA USA

${ }^{2}$ Department of Civil and Environmental Engineering Northeastern University, Boston, MA USA

${ }^{3}$ Direction de santé publique de Montréal, Montréal, Québec, Canada

${ }^{4}$ Département de Médecine Sociale et Préventive, Université de Montréal, Montréal, Québec, Canada

${ }^{5}$ Department of Civil Engineering and Applied Mechanics, McGill University, Montréal, Québec, Canada

${ }^{6}$ Department of Epidemiology, Harvard School of Public Health, Boston, MA, USA

${ }^{7}$ Department of Environmental Health, Harvard School of Public Health, Boston, MA, USA ${ }^{8}$ Department of Orthopaedic Surgery, Brigham and Women's Hospital, Harvard Medical School, Boston, MA, USA

\section{Correspondence to}

Dr Anne Lusk, Harvard School of Public Health, 665 Huntington Avenue, Building II, Room 314, Boston, MA 02115, USA; annelusk@hsph.harvard.edu

Accepted 1 December 2010 Published Online First 9 February 2011

This paper is freely available online under the BMJ Journals unlocked scheme, see http:// injuryprevention.bmj.com/site/ about/unlocked.xhtml

\section{ABSTRACT}

Most individuals prefer bicycling separated from motor traffic. However, cycle tracks (physically separated bicycle-exclusive paths along roads, as found in The Netherlands) are discouraged in the USA by engineering guidance that suggests that facilities such as cycle tracks are more dangerous than the street. The objective of this study conducted in Montreal (with a longstanding network of cycle tracks) was to compare bicyclist injury rates on cycle tracks versus in the street. For six cycle tracks and comparable reference streets, vehicle/bicycle crashes and health record injury counts were obtained and use counts conducted. The relative risk (RR) of injury on cycle tracks, compared with reference streets, was determined. Overall, 2.5 times as many cyclists rode on cycle tracks compared with reference streets and there were 8.5 injuries and 10.5 crashes per million bicyclekilometres. The RR of injury on cycle tracks was 0.72 (95\% Cl 0.60 to 0.85 ) compared with bicycling in reference streets. These data suggest that the injury risk of bicycling on cycle tracks is less than bicycling in streets. The construction of cycle tracks should not be discouraged.

Bicycling could address obesity, cancer, stroke, diabetes, asthma, mortality and pollution; ${ }^{1}{ }^{2}$ however, the bicycling environment is a limiting factor. The predominant bicycle facilities in The Netherlands and Denmark are cycle tracks, or bicycle paths along streets that are physically separated from motor traffic, bicycle-exclusive and with a parallel sidewalk. ${ }^{3}$ Due to the separation from vehicles afforded by $29000 \mathrm{~km}$ of cycle tracks in The Netherlands plus other initiatives, ${ }^{4} 27 \%$ of Dutch trips are by bicycle, $55 \%$ are women, and the bicyclist injury rate is 0.14 injured/million $\mathrm{km} .{ }^{5}$ In the USA, $0.5 \%$ of commuters bicycle to work, only $24 \%$ of adult cyclists are women, ${ }^{6}$ and the injury rate of bicyclists is at least 26 times greater than in The Netherlands. ${ }^{5}$ The chief obstacle to bicycling, especially for women, ${ }^{7}$ children $^{8}$ and seniors ${ }^{9}$ is perceived danger of vehicular traffic. This perceived danger from cars appears to be real, ${ }^{10}$ as corroborated by survey participants who prefer cycle tracks over roads. $^{11}$

Cycle track construction has been hampered in the USA by engineering guidance in the American Association of State Highway and Transportation Officials (AASHTO) 'Guide for the development of bicycle facilities ${ }^{\prime 12}$ which cautions against building two-way paths along, but physically separated from, a parallel road. AASHTO states that sidewalk bikeways are unsafe and implies the same about shared-use paths parallel to roads, listing numerous safety concerns and permitting their use only in special situations. Cycle tracks, which can be one or two-way and resemble shared-use paths, are not mentioned in the AASHTO bike guide. A longstanding, and yet not rigorously proved, philosophy in the USA has suggested instead that 'bicyclists fare best when they behave as, and are treated as, operators of vehicles. ${ }^{\prime 13}$ The details about cycle tracks in the Dutch bicycle design manual CROW ${ }^{3}$ and crash rate comparisons between the USA and The Netherlands ${ }^{5}$ have been dismissed by vehicular cycling proponents, ${ }^{14}$ with arguments of nontransferability to the American environment. Cycle tracks have been controversial, especially due to conflicting studies with warnings of increased crash rates. ${ }^{15}$ The warnings, which in the USA result in striped bike lanes but not cycle tracks, come without any substantial study of the safety of North American cycle tracks. Using existing crash and injury data from Montreal, Canada, a city with a network of cycle tracks in use for more than 20 years, this study compared bicyclists' injury and crash rates with published data and bicyclists' injury rates on cycle tracks versus in the street.

\section{METHODS}

We studied six cycle tracks in Montreal that are two-way on one side of the street. Each cycle track was compared with one or two reference streets without bicycle facilities that were considered alternative bicycling routes. One reference street was a continuation of the street with the cycle track; the remaining streets were parallel to the cycle track with the same cross streets as endpoints and, therefore, subject to approximately the same intersection frequency and cross traffic as the cycle track.

\section{Injury and vehicle/bicycle crash rates per bicycle-kilometre}

The injury and crash rates for each cycle track were determined from the emergency medical response (EMR) database ${ }^{16}$ and police-recorded vehicle/ bicycle crashes and estimated on the cycle tracks per bicycle-km. Automated 24-h bicycle counts on Montreal cycle tracks are available for selected years, with 20-64 days in each sample from May to September. We used linear interpolation between the 2000 and 2008 samples to determine average daily use for the date ranges of the injury and crash counts. Average daily use was converted to annual use by multiplying by 200 'effective days' in the 1 April to 15 November bicycling season (when seasonal cycle tracks are open), recognising that 
bicycle use tends to be less in April, October and November than in the sampled months. Use estimates were converted to bicycle$\mathrm{km}$ by multiplying by segment length and the fraction of the cycle track's length ridden per cyclist. This fraction, which ranged from 0.6 to 0.9 , was determined using expert judgement considering the cycle track length and opportunities for turning on and off.

\section{Relative Risk (RR) of injury for cycle tracks}

The RR of the cycle track compared with the reference street was estimated using bicyclist counts and injuries from the EMR database. ${ }^{16}$ Although injury (EMR) and bicycle/vehicle crash data from police records overlap strongly, the injury data have been shown to be more exhaustive ${ }^{17}$ and were available for a longer period. Injury counts were determined for the 1 April to 15 November bicycling season and within $15 \mathrm{~m}$ of each street centerline. For comparability with exposure data, it was important to exclude individuals injured at intersections who may have been riding on a cross street; however, the EMR database does not indicate which street the injured cyclist was using. Therefore, using the police crash database we determined for each section studied the fraction of bicycle/vehicle crashes involving cyclists who were riding on cross streets, and reduced injury counts by that fraction.

Historical bicycle counts were available for the cycle tracks but not the reference streets. To obtain an unbiased measure of relative exposure, simultaneous $2 \mathrm{~h}$ bicycle counts were conducted at parallel counting sites on each cycle track and its reference street(s). Using a ratio of simultaneous counts eliminates systematic effects on bicycle use such as weather, time and day. The simultaneous counts were made during mild weather commuting hours in 2009.

The RR of injury for each cycle track was calculated as:

$$
R R=\frac{\frac{\text { injuries }_{\text {track }}}{\text { bikes }_{\text {track }}}}{\frac{\text { injuries ref }_{\text {ref }}}{\text { bikes }_{\text {ref }}}}
$$

where injuries track $_{\text {and injuries }}$ ref are the count of injuries on the cycle track and reference street(s), respectively, and bikes track $_{\text {and }}$ and bikes $_{\text {ref }}$ are the corresponding cyclist counts.

Ninety-five percent CI were calculated using the variance of $\log$ (ratio) based on a Poisson distribution for incidents. CI that did not include 1 were considered statistically significant. RR for all cycle tracks was calculated similarly using the summed data from all the observations.

\section{Relative danger from vehicular traffic}

Reference streets were selected with vehicular traffic danger (volume, speed, heavy vehicles) as similar as possible to their cycle track; however, it was impossible to achieve exact similarity. Therefore, to compare the vehicular traffic danger, we also calculated the ratio of motor vehicle occupant (MVO) injuries on the cycle track street to MVO injuries on the reference street. MVO injury counts are considered a surrogate for traffic danger a bicyclist might face on a given street apart from any treatment.

\section{RESULTS}

All six cycle tracks were two-way on one side of the street and separated from traffic by raised medians, parking lanes, or delineator posts. There were 8.5 injuries and 10.5 crashes per million bicycle- $\mathrm{km}$. The Brébeuf and Maisonneuve cycle tracks stand out as safer than the other four (table 1).

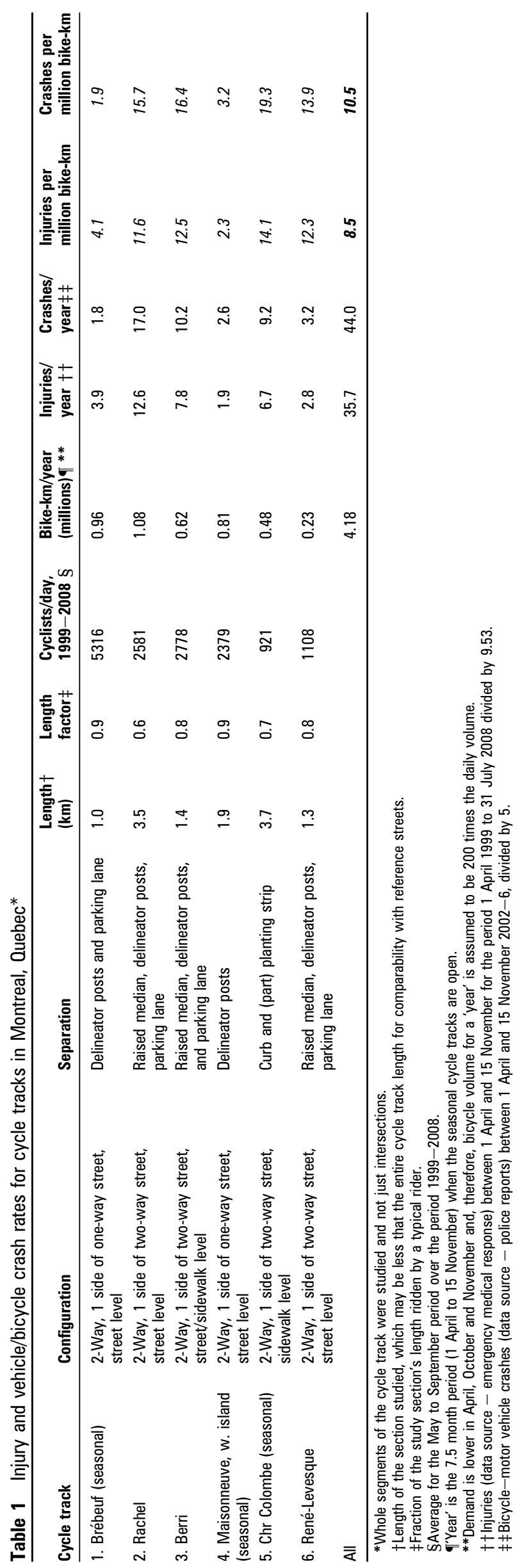


Table 2 RR of injury for cycle tracks compared to similar on-street routes for Montreal, Quebec*

\begin{tabular}{|c|c|c|c|c|c|c|c|c|}
\hline \multirow[b]{2}{*}{ Cycle track $\dagger$} & \multirow[b]{2}{*}{ Reference street $\neq$} & \multirow[b]{2}{*}{ Limiting cross streets } & \multirow[b]{2}{*}{$\begin{array}{l}\text { Length } \\
(\mathrm{km})\end{array}$} & \multicolumn{2}{|c|}{ Cycle track } & \multicolumn{2}{|c|}{ Reference street } & \multirow[b]{2}{*}{ RR $(95 \%$ Cl) 9} \\
\hline & & & & $\begin{array}{l}\text { 2-h } \\
\text { bike } \\
\text { count }\end{array}$ & $\begin{array}{l}\text { EMR- } \\
\text { reported } \\
\text { injuries } \S\end{array}$ & $\begin{array}{l}2-h \\
\text { bike } \\
\text { count }\end{array}$ & $\begin{array}{l}\text { EMR- } \\
\text { reported } \\
\text { injuries } \S\end{array}$ & \\
\hline 1. Brébeuf & St Denis (N) & Rachel - Laurier & 1.0 & 1193 & 37 & 437 & 32 & $0.42(0.26$ to 0.68$)$ \\
\hline 2. Rachel & Mont Royal & St Urbain - Marquette & 3.5 & 990 & 120 & 613 & 63 & $1.18(0.87$ to 1.60$)$ \\
\hline 3. Berri & St Denis (S) & Cherrier - Viger & 1.4 & 763 & 74 & 134 & 27 & $0.48(0.31$ to 0.75$)$ \\
\hline \multirow[t]{3}{*}{ 4. Maisonneuve } & Both & Claremont - Wood & 1.9 & 547 & 18 & $176^{* *}$ & 18 & $0.32(0.17$ to 0.62$)$ \\
\hline & Sherbrooke (W) & & & & & 129 & 14 & 0.30 \\
\hline & Ste Catherine & & & & & 47 & 4 & 0.39 \\
\hline \multirow[t]{3}{*}{ 5. Christophe Colomb } & Both & Gouin - Jarry & 3.7 & 407 & 64 & 122 & 19 & $1.01(0.61$ to 1.68$)$ \\
\hline & Saint-Hubert & & & & & 45 & 9 & 0.79 \\
\hline & Christophe Colomb (S) & Villeray - Rosemont & 2.3 & & & 77 & 10 & 1.21 \\
\hline 6. René Levesque & Sherbrooke (E) & Lorimier - St Hubert & 1.3 & 109 & 27 & 130 & 32 & $1.01(0.60$ to 1.68$)$ \\
\hline All & & & 15.1 & 4009 & 340 & 1612 & 191 & $0.72(0.60$ to 0.85$)$ \\
\hline
\end{tabular}

Compared with bicycling on a reference street, the overall RR of injury on a cycle track was 0.72 (95\% CI 0.60 to 0.85 ); thus, these cycle tracks had a $28 \%$ lower injury rate. Three of the cycle tracks exhibited RR less than 0.5 , and none showed a significantly greater risk than its reference street. Overall, 2.5 times as many cyclists used the cycle tracks compared with the reference streets (table 2).

The relative danger from vehicular traffic of the cycle tracks compared with their reference streets was close to 1.0 overall, but with a wide range (table 3 ). Not surprisingly, the Brébeuf and Maisonneuve cycle tracks with lowest crash rate and relative injury risk (tables 1 and 2) also had the lowest relative danger from vehicular traffic (table 3). Yet even for the four cycle tracks on streets with vehicular traffic danger similar to or greater than its reference street, the cycle tracks still had less or a similar risk of injury.

\section{DISCUSSION}

Contrary to AASHTO's safety cautions about road-parallel paths and its exclusion of cycle tracks, our results suggest that two-way cycle tracks on one side of the road have either lower or similar injury rates compared with bicycling in the street without bicycle provisions. This lowered risk is also in spite of the less-than-ideal design of the Montreal cycle tracks, such as lacking parking setbacks at intersections, a recommended practice. ${ }^{18}$

While the goal of this study was to consider both one and twoway cycle tracks, all of the Montreal cycle tracks were two-way with half the bicyclists riding in a direction opposite to that of the closest vehicular traffic, a practice not favoured by AASHTO. Although the Montreal cycle tracks were two-way, they had lower or similar risk compared with the road. The Dutch CROW bicycle guidelines suggest that one-way cycle tracks are even safer. $^{3}$

The crash rate for Montreal's cycle tracks (10.5 crashes per million bicycle-km) is low compared with the few and inconsistent crash rates in the literature. When calculated to include only vehicle/bicycle crashes, these rates range from $3.75^{5}$ to $54^{19}$ in the USA and from $46^{20}$ to $67^{21}$ in Canada. The injury rate ( 8.5 injuries per million bicycle-km) lacks comparable data in the literature, partly because few communities have accessible bicycle-incident ambulance records. Although the Brébeuf and Maisonneuve cycle tracks were safer, the sample of six cycle

Table 3 Relative danger from vehicular traffic*

\begin{tabular}{|c|c|c|c|c|}
\hline \multirow[b]{2}{*}{ Cycle track street } & \multirow[b]{2}{*}{ Reference street } & \multicolumn{2}{|c|}{ MVO injuries † } & \multirow[b]{2}{*}{$\begin{array}{l}\text { Relative traffic danger of cycle } \\
\text { track street }(95 \% \mathrm{CI}) \neq\end{array}$} \\
\hline & & $\begin{array}{l}\text { Cycle track } \\
\text { street }\end{array}$ & $\begin{array}{l}\text { Reference } \\
\text { street }\end{array}$ & \\
\hline 1. Brébeuf & St Denis (N) & 8 & 90 & $0.09(0.04$ to 0.18$)$ \\
\hline 2. Rachel & Mont Royal & 86 & 69 & $1.25(0.91$ to 1.73$)$ \\
\hline 3. Berri & St Denis (S) & 127 & 116 & $1.09(0.85$ to 1.41$)$ \\
\hline \multirow[t]{3}{*}{ 4. Maisonneuve } & Both & 13 & $59 \S$ & $0.22(0.12$ to 0.40$)$ \\
\hline & Sherbrooke (W) & & 72 & \\
\hline & Ste Catherine & & 46 & \\
\hline \multirow[t]{3}{*}{ 5. Christophe Colomb } & Both & 367 & $217 \S$ & 1.69 (1.43 to 2.00$)$ \\
\hline & Saint-Hubert & & 268 & \\
\hline & Christophe Colomb (S) & & 166 & \\
\hline 6. René Levesque & Sherbrooke (E) & 196 & 205 & $0.96(0.79$ to 1.16$)$ \\
\hline All & All & 797 & 756 & $1.05(0.95$ to 1.16$)$ \\
\hline
\end{tabular}


Table 4 Crash RR from Wachtel and Lewiston ${ }^{22}$ data with non-intersection crashes included*

\begin{tabular}{|c|c|c|c|c|c|c|c|c|}
\hline & \multicolumn{2}{|c|}{ Sidewalk } & \multicolumn{2}{|c|}{ Roadway } & \multicolumn{2}{|l|}{ All } & \multirow{2}{*}{$\begin{array}{l}\text { RR, sidewalk versus } \\
\text { in-street }(95 \% \mathrm{CI}) \dagger\end{array}$} & \multirow[b]{2}{*}{ p Value $\ddagger$} \\
\hline & Riders & Crashes & Riders & Crashes & Riders & Crashes & & \\
\hline \multicolumn{9}{|l|}{ Intersection only§ } \\
\hline All cyclists & 971 & 41 & 2005 & 48 & 2976 & 89 & 1.76 (1.16 to 2.68$)$ & 0.01 \\
\hline $\begin{array}{l}\text { Bicycling in same direction } \\
\text { as closest traffic lane }\end{array}$ & 656 & 13 & 1897 & 43 & 2553 & 56 & $0.87(0.47$ to 1.63$)$ & 0.56 \\
\hline \multicolumn{9}{|l|}{ All crashes $₫$} \\
\hline All cyclists & 971 & 41 & 2005 & 79 & 2976 & 120 & $1.07(0.73$ to 1.56$)$ & 0.79 \\
\hline $\begin{array}{l}\text { Bicycling in same direction } \\
\text { as closest traffic lane }\end{array}$ & 656 & 13 & 1897 & 71 & 2553 & 84 & $0.53(0.29$ to 0.96$)$ & 0.02 \\
\hline
\end{tabular}

tracks was too small to determine which factors make some safer.

In one of the few comparisons of bicycling in the street versus bicycling on a separated path parallel to the street in the USA, Wachtel and Lewiston ${ }^{22}$ determined a relative crash risk of 1.8 for bicycling on sidewalks which had been designated as bikeways, compared with bicycling in the adjacent street in Palo Alto, California. However, their study considered only intersection crashes, omitting non-intersection crashes that include being hit from behind, sideswiped, or struck by a car door. The authors, though, reported that $26 \%$ of cyclist-motor vehicle collisions city-wide in Palo Alto were non-intersection crashes. If non-intersection crashes are included to match this $26 \%$ proportion, reanalysis of the Wachtel and Lewiston ${ }^{22}$ data in the article shows that there is no significant difference in risk

\section{What is already known on this subject}

- Individuals, in particular women, children, and seniors, prefer to bicycle separated from motor traffic.

- Cycle tracks (physically-separated bicycle-exclusive paths along roads) exist and continue to be built in The Netherlands where $27 \%$ of all trips are by bicycle and $55 \%$ of bicycle riders are female.

- Engineering guidance in the United States has discouraged bicycle facilities that resemble cycle tracks, including parallel sidepaths and sidewalk bikeways, suggesting that these facilities and cycle tracks are more dangerous than bicycling in the street.

\section{What this study adds}

- Overall, $21 / 2$ times as many cyclists rode on the cycle tracks compared with the reference streets.

- There were 8.5 injuries and 10.5 crashes per million-bicycle kilometers respectively on cycle tracks compared to published injury rates ranging from 3.75 to 67 for bicycling on streets. The relative risk of injury on the cycle track was $0.72(95 \%$ $\mathrm{Cl}=0,60-0.85)$ compared with bicycling in the reference streets.

- Cycle tracks lessen, or at least do not increase, crash and injury rates compared to bicycling in the street. between the sidewalk bikeway and the street (table 4). For bicyclists riding in the same direction as traffic, as would be case with one-way cycle tracks, sidewalk bikeways carried only half the risk of the street. Therefore, the Wachtel and Lewiston ${ }^{22}$ data, when corrected to include non-intersection crashes, corroborate our findings that separated paths are safer or at least no more dangerous than bicycling in the street. Furthermore, as the most common cause of fatal bicyclist collisions in urban areas is overtaking, ${ }^{23}$ it is probable that an analysis accounting for the severity of injury would be still more favourable towards cycle tracks.

Our study considered whole segments of cycle tracks and not just intersections, measured bicycle exposure directly, and included appropriate comparison groups. The study, though, only included analysis of six cycle tracks, all of which were twoway and in the same city, and lacked injury severity data. This research underscores the need for better bicycle counting and injury surveillance and for additional safety studies, particularly of one-way cycle tracks, intersections, injury severity and other factors that affect cycle track safety.

\section{IMPLICATIONS FOR POLICY}

Public health and bicycling advocates in the USA have faced a dichotomy, believing from surveys and European experience that cycle tracks encourage more bicycling, yet being warned that they lead to higher crash and injury rates. Our results suggest that cycle tracks lessen, or at least do not increase, crash and injury rates compared with the street. The construction of cycle tracks should not be discouraged.

Acknowledgements The authors would like to thank Kevin Manaugh (McGill University) and Nathalie Valois (Montreal police), who performed the geographical queries to extract data from the crash database, and Qi Sun and Elaine Hoffman for a review of the statistics.

Funding ACL was supported by a Ruth L Kirschstein National Research Service Award, F32 HL083639 from the National Institutes for Health, National Heart, Lung and Blood Institute. LFM-M is supported for data collection by the Natural Sciences and Engineering Research Council of Canada (discovery grant - individual).

\section{Competing interests None.}

Ethics approval The Harvard School of Public Health IRB reviewed this protocol and found that approval was not required. The HSPH IRB made an exemption determination.

Contributors PGF had full access to the data in the study and takes responsibility for the integrity of the data and the accuracy of the data analysis. Conception and design: ACL and PGF. Acquisition of data: ACL, PGF, PM and LFM-M. Analysis and interpretation of data: ANL, PGF, PM, LFM-M, WCW and JTD. Drafting of manuscript: ACL, PGF. Critical revision for intellectual content: ACL, PGF, PM, LFM-M, WCW and JTD. Statistical expertise: ACL, PGF, PM, LFM-M, WCW and JTD. Administrative, technical or material support: WCW. Study supervision: PGF, WCW and JTD. 
Provenance and peer review Not commissioned; externally peer reviewed.

\section{REFERENCES}

1. Lusk AC, Mekary RA, Feskanich D, et al. Bicycle riding, walking, and weight gain in premenopausal women. Arch Intern Med 2010:170:1050-6.

2. Andersen LB, Schnohr P, Schroll M, et al. All-cause mortality associated with physical activity during leisure time, work, sports, and cycling to work. Arch Intern Med 2000;160:1621-8.

3. CROW. Design manual for bicycle traffic. Netherlands: National Information and Technology Platform for Infrastructure, Traffic, Transport, and Public Space, 2006.

4. Verkeersnet.nl. Fietsersbond: Veel meer fietspad dan bekend in ons land. 2009 http://www.verkeersnet.nl/1782/fietsersbond-veel-meer-fietspad-dan-bekend-in-onsland/ (accessed 21 Apr 2010).

5. Pucher J, Buehler R. Making cycling irresistible: lessons from the Netherlands, Denmark, and Germany. Transport Reviews 2008;28:1-34.

6. U.S. Census Bureau. American community survey 3-year estimates $B 08006$ sex of workers by means of transportation to work - universe - workers 16 years and over. 2006-2008. http://factfinder.census.gov/servlet/DTTable? bm=yggeo id =01000US\&-ds name $=$ ACS 2008 3YR G00 \&- lang =enqcaller $=$ geoselectধ-state $=$ dt $q-$ format $=$ \&-

mt name $=$ ACS 2008 3YR G2000 B08006 (accessed 26 Jan 2010).

7. Garrard J, Rose G, Lo SK. Promoting transportation cycling for women: the role of bicycle infrastructure. Prev Med 2008;46:55-9.

8. Mehan TJ, Gardner R, Smith GA, et al. Bicycle-related injuries among children and adolescents in the United States. Clin Pediatr (Phila) 2009;48:166-73.

9. Hayes JS, Henslee B, Ferber J. Bicycle injury prevention and safety in senior riders. J Trauma Nurs 2003:10:66-8.
10. Haileyesus T, Annest JL, Dellinger AM. Cyclists injured while sharing the road with motor vehicles. Inj Prev 2007;13:202-6.

11. Winters $\mathbf{M}$, Teschke K. Route preferences among adults in the near market for bicycling: findings of the cycling in cities study. Am J Health Promot 2010;25:40-7.

12. American Association of State Highway and Transportation Officials. Guide for the development of bicycle facilities. Washington, DC: AASHTO, 1999

13. Forester J. Effective cycling. Cambridge: The MIT Press, 1984.

14. Forester J. The bikeway controversy. Transportation Quarterly. Washington, D.C. USA, Spring, 2001:55

15. Jensen S. Bicycle tracks and lanes: a before-and-after study. Transportation Research Board 87th Annual Meeting, 2008-1-13 to 2008-1-17. Washington, DC. 2008:15

16. Morency P, Cloutier MS. From targeted "black spots" to area-wide pedestrian safety. Inj Prev 2006;12:360-4.

17. Langley JD, Dow N, Stephenson S, et al. Missing cyclists. Inj Prev 2003;9:376-9

18. Velo Quebec. Technical handbook of bikeway design. 2nd ed. Quebec: Ministere des Transport du Quebec and the Secretariat au Loisir et au Sport, 2003.

19. Dennerlein JT, Meeker JD. Occupational injuries among Boston bicycle messengers. Am J Ind Med 2002:42:519-25.

20. Aultman-Hall L, Hall FL. Ottawa-Carleton commuter cyclist on- and off-road incident rates. Accid Anal Prev 1998;30:29-43.

21. Aultman-Hall L, Kaltenecker MG. Toronto bicycle commuter safety rates. Accid Anal Prev 1999;31:675-86.

22. Wachtel A, Lewiston D. Risk factors for bicycle-motor vehicle collisions at intersections. ITE Journal of Institute of Transportation Engineers 1994:30-5.

23. McCarthy M, Gilbert K. Cyclist road deaths in London 1985-1992: drivers, vehicles manoeuvres and injuries. Accid Anal Prev 1996;28:275-9.

\section{Dog attacks in Canada's North}

Following a recent mauling of a 6 -year-old girl by four dogs in an Inuit community, a study by a veterinarian in Thunder Bay, Ontario, based on media reports, revealed that 'native communities suffer bite wounds or mauling deaths from dogs at rates more than 100 times that of the rest of Canada'. (Postmedia news, Gazette, December 17, 2010)

Collected and edited by Barry Pless 